\title{
Editorial of Special Issue “Drones for Biodiversity Conservation and Ecological Monitoring"
}

\author{
Ricardo Díaz-Delgado ${ }^{1, *(1)}$ and Sander Mücher ${ }^{2}$ \\ 1 Remote Sensing and GIS Laboratory (LAST-EBD). Estación Biologica de Doñana. CSIC. Avda. Américo \\ Vespucio 26, 41092 Sevilla, Spain \\ 2 Wageningen Environmental Research (WENR), Wageningen University and Research, Building 101, \\ Droevendaalsesteeg 3, P.O Box 47,6700 AA Wageningen, The Netherlands; sander.mucher@wur.nl \\ * Correspondence: rdiaz@ebd.csic.es; Tel.: +34-954-232340
}

Received: 2 June 2019; Accepted: 3 June 2019; Published: 7 June 2019

\begin{abstract}
Unmanned Aerial Vehicles (UAV) have already become an affordable and cost-efficient tool to quickly map a targeted area for many emerging applications in the arena of Ecological Monitoring and Biodiversity Conservation. Managers, owners, companies and scientists are using professional drones equipped with high-resolution visible, multispectral or thermal cameras to assess the state of ecosystems, the effect of disturbances, or the dynamics and changes of biological communities inter alia. It is now a defining time to assess the use of drones for these types of applications over natural areas and protected areas. UAV missions are increasing but most of them are just testing its applicability. It is time now to move to frequent revisiting missions, aiding in the retrieval of important biophysical parameters in ecosystems or mapping species distributions. This Special Issue is aimed at collecting UAV applications contributing to a better understanding of biodiversity and ecosystem status, threats, changes and trends. Submissions were welcomed from purely scientific missions to operational management missions, evidencing the enhancement of knowledge in: Essential biodiversity variables and ecosystem services mapping; ecological integrity parameters mapping; long-term ecological monitoring based on UAVs; mapping of alien species spread and distribution; upscaling ecological variables from drone to satellite images: methods and approaches; rapid risk and disturbance assessment using drones, ecosystem structure and processes assessment by using UAVs, mapping threats, vulnerability and conservation issues of biological communities and species; mapping of phenological and temporal trends and habitat mapping; monitoring and reporting of conservation status.
\end{abstract}

Keywords: UAVs; ecological monitoring; biological conservation; drone mapping; biodiversity; phenology

\section{Special Issue Overview}

This special issue was proposed in 2017 , November the $14^{\text {th }}$, and kindly accepted on November the $21^{\text {st }}$. Announcements were spread during January 2018 through many different mailing lists dealing with remote sensing and Geographic Information System, as well as personal invitations to a list of 232 authors with previous publications, on the use of UAVs in relation to the topics. First abstracts were then submitted immediately after the call, having the first accepted and published paper on $12^{\text {th }}$ April. The initial deadline was scheduled for $31^{\text {st }} \mathrm{July}$, but it was decided to extend to $31^{\text {st }}$ October.

A total amount of 12 manuscripts were submitted from which 10 were finally accepted and published, including one review paper and 11 research articles. All of them were peer-reviewed by scientific reviewers suggested by authors and the editorial board. Some of the manuscripts had to prepare full re-submissions according to reviewer's suggestions. Rejections were merely related to be out of scope. MDPI gently allowed submission of manuscripts which had been previously 
compromised by authors with abstracts until November 2018. While the Special Issue was open, flyers were kindly prepared by MDPI which were distributed in several conferences and research project meetings.

\section{Special Issue Topics}

A literature search using ISI Web of Science with the option, TS (UAV or UAS or Drone), provided 28,485 records from which $30 \%$ were classified under, engineering electrical electronic, $13 \%$ under automation control systems and in the $3 \mathrm{~d}$ position, remote sensing was found. The publication year starts in 2010 with 720 publications and increases to 4723 in 2018. The USA leads the academic production followed by China. By adding, and TS (REMOTE SENSING), records drop down to a total of 1860, with just 37 indexed papers in 2010 to 475 in 2018. From these, 782 are strictly classified under the remote sensing category and just 161 under the Environmental sciences category. This quick literature search points out the delay in the application of drones for environmental issues in relation to other knowledge fields. Additionally, it reveals the lack of published papers in this area.

This special issue has contributed to the spread the many diverse applications of drones in ecological monitoring and biodiversity conservation. Three of the published articles have addressed the main issues and opportunities in wildlife detection and mapping, and in both cases applied to protected species. Bonnin et al. [1] used fixed-wing drones by means of in line transects and grid missions to locate Chimpanzee nests in Tanzania. Potential unknown nests were identified although many nests located in the middle of tree crowns could not be detected. The authors suggest the combination of lower altitude flights with multirotor drones, multispectral cameras and oblique surveys can lead to reduce false alerts and increase nest detectability. In any case, this study indicates that one of the most widely used application of drones in wildland management, although most of them remain unpublished. Similarly, Afán et al. [2] address the suitability of drone-borne images to automatically map and count Glossy Ibis nests. While monitoring bird populations and productivity, the staff have to recurrently visit the colony, and once per year enter the colony to confirm the census. This effort is clearly benefited from the accurate counting by drone-borne images which clearly appear as one of the most efficient application in environmental monitoring. Machine learning techniques are contributing to enhance counting by identifying different species. One interesting option to locate wildlife is, rather than feature identification or mapping, is to use drones for radio-tracking. This is the subject addressed by Desrochers et al. [3] in its published paper, where a VHF (Very High Frequency) receiver was mounted in the drone to test the accuracy in locating radio-transmitters in a dense boreal forest. The results demonstrated that drone radio-tracking offers an efficient alternative to the more labor-intensive, traditional approaches for radio-tracking small birds, amphibians, or small mammals in rugged terrain. Further, more essays have to be completed to evaluate the limitations while tracking moving animals and defining adequate flight paths or search patterns to find close signals. All three studies are good examples of the wide spectrum brightly depicted by Jiménez López and Mulero Pázmány [4] in the special issue review. The authors summarize the search for published contributions of drone applications in wildlife monitoring and management, ecosystem monitoring, law enforcement, ecotourism and environmental management and disaster response. An immense diversity of applications reveals the wide flexibility and ingenuity of drone missions to retrieve critical spatial data dealing with environmental monitoring and assessment.

A set of published articles under this special issue point out the important role of drone-borne multispectral images for validation and upscaling of satellite images and derived products. This is the case for the papers by Díaz-Delgado et al. [5], Pla et al. [6] and Canisius et al. [7]. The first paper takes advantage of the high spatial resolution of multispectral images acquired over Doñana marshes to retrieve relevant monitoring indicators related to ecological integrity of the ecosystem. The intermediate scale provided by multispectral drone images are used to enlarge ground-truth for Sentinel-2 images, which exposes a new methodological approach to assess the accuracy of large scale ecosystem essential variables provided by Earth observation satellites, such as the Copernicus 
European program or the international GEO-GEOSS. Similarly, Pla et al [6], used NDVI (Normalized Difference Vegetation Index) from multispectral images from a multirotor drone to evaluate damages by one threatened bird species on rice paddies. Fine grain damages accounted from drone images was later related to Sentinel-2 NDVI images in order to extend the assessment to larger areas. Although the study was carried out on agricultural area, such agro-systems are habitats for the wildlife and therefore, payments for damages have to be properly estimated to preserve biodiversity. Finally, Canisius et al. [7], developed a multi-sensor platform to reliably measure land surface albedo providing a strong relationship between direct total shortwave albedo measurements from the pyranometer mounted on the UAV (Unmanned Aerial System) with Sentinel-2 and Landsat-8 estimates. This paper demonstrates how drones can bridge the gap between fixed point, in-situ albedo measurements and pixel-level measurements by satellites.

The special issue has also revisited classical remote sensing approaches to assist in post-fire recovery monitoring and vegetation mapping using drones. Melville et al. [8] presented an excellent example of accurate mapping of grassland communities with the use of a hyperspectral sensor. This technology has quickly become affordable and light enough to be mounted in powerful multirotor drones allowing to retrieve a continuum spectrum of plant spectral signatures. The authors also made use of one of the most advantageous outcomes of drone mapping-point cloud and the derived digital surface models. From this information, always inherently produced by drone gridded missions, canopy height models as a function of bare ground models can also be retrieved. Their classification procedure using random forest was enhanced with this valuable information. Fine scale and accurate habitat mapping and monitoring with drones is evidenced by what becomes a reliable technique as inputs in habitat assessment, such as the reporting on conservation status requested by the Natura 2000 European directive. Larrinaga and Brotons [9] also harnessed the Structure from Motion (SfR) to derive canopy height and together, with several multispectral vegetation indices, use it to model tree DBH (Diameter at the Brest Height) in a 20-year old burned area. The authors predict forest recovery after fire with $\mathrm{DBH}$ as an indicator of plant canopy. The last, but not least, contribution by Díaz-Delgado et al. [10] shows a very innovative proposal to use drones in long-term monitoring of experimental climate change plots. The authors stressed the need to complement in situ measurements in order to complement them by adding spatially explicit information to the effect of treatments on native grassland communities. One of the findings reveals that heterogeneity in plant response to treatments may easily hide species specific trends and changes.

There were no contributions of applications using LiDAR sensors onboard of drones which is known to be widely used on natural areas with many different objectives in the framework of ecological monitoring. Researchers and technicians are invited to submit their studies to Drones Open Access journal. The authors look forward to have our journal indexed in the close future.

\section{Message to Conservationists, Practitioners, Managers and Ecologists}

Nowadays, the joint development of sensors, drones and image analysis techniques as machine learning is providing an excellent opportunity to aid in environmental conservation and management. Furthermore, not only rapid missions to assess the effects of sudden disturbances, but periodical surveys carried out by programmed flights by drones, are providing invaluable assistance in decision making as spatially explicit ecological and biodiversity monitoring. It is a matter of researchers to provide and diffuse the suitability of drones to carry out very specific and timely missions enhancing the necessary labor of day-to-day nature monitoring and management. There is also much discussion about the aviation rules that should enable E-VLOS and B-VLOS to increase the operational use for agriculture and nature applications. On the other hand, more research is needed about disturbances of UAVs on species. The outcome of these discussions can have a big impact on the further use of UAVs. Nevertheless, there is a wide consensus on the upcoming strong increase in the use of drones for these topics. 
Acknowledgments: The first assistant editor, Ms. Trista Liu, provided great support to guest editors, Ricardo Díaz-Delgado and Sander Mücher, until her handover to the new editorial officer, Elvis Wang, who dealt with most of the edition of this Special Issue.

\section{References}

1. Bonnin, N.; Van Andel, A.C.; Kerby, J.T.; Piel, A.K.; Pintea, L.; Wich, S.A. Assessment of Chimpanzee Nest Detectability in Drone-Acquired Images. Drones 2018, 2, 17. [CrossRef]

2. Afán, I.; Máñez, M.; Díaz-Delgado, R. Drone Monitoring of Breeding Waterbird Populations: The Case of the Glossy Ibis. Drones 2018, 2, 42. [CrossRef]

3. Desrochers, A.; Tremblay, J.A.; Aubry, Y.; Chabot, D.; Pace, P.; Bird, D.M. Estimating Wildlife Tag Location Errors from a VHF Receiver Mounted on a Drone. Drones 2018, 2, 44. [CrossRef]

4. Jiménez López, J.; Mulero-Pázmány, M. Drones for Conservation in Protected Areas: Present and Future. Drones 2019, 3, 10. [CrossRef]

5. Díaz-Delgado, R.; Cazacu, C.; Adamescu, M. Rapid Assessment of Ecological Integrity for LTER Wetland Sites by Using UAV Multispectral Mapping. Drones 2019, 3, 3. [CrossRef]

6. Pla, M.; Bota, G.; Duane, A.; Balagué, J.; Curcó, A.; Gutiérrez, R.; Brotons, L. Calibrating Sentinel-2 Imagery with Multispectral UAV Derived Information to Quantify Damages in Mediterranean Rice Crops Caused by Western Swamphen (Porphyrio porphyrio). Drones 2019, 3, 45. [CrossRef]

7. Canisius, F.; Wang, S.; Croft, H.; Leblanc, S.G.; Russell, H.A.J.; Chen, J.; Wang, R. A UAV-Based Sensor System for Measuring Land Surface Albedo: Tested over a Boreal Peatland Ecosystem. Drones 2019, 3, 27. [CrossRef]

8. Melville, B.; Lucieer, A.; Aryal, J. Classification of Lowland Native Grassland Communities Using Hyperspectral Unmanned Aircraft System (UAS) Imagery in the Tasmanian Midlands. Drones 2019, 3, 5. [CrossRef]

9. Larrinaga, A.R.; Brotons, L. Greenness Indices from a Low-Cost UAV Imagery as Tools for Monitoring Post-Fire Forest Recovery. Drones 2019, 3, 6. [CrossRef]

10. Díaz-Delgado, R.; Ónodi, G.; Kröel-Dulay, G.; Kertész, M. Enhancement of Ecological Field Experimental Research by Means of UAV Multispectral Sensing. Drones 2019, 3, 7. [CrossRef]

(C) 2019 by the authors. Licensee MDPI, Basel, Switzerland. This article is an open access article distributed under the terms and conditions of the Creative Commons Attribution (CC BY) license (http://creativecommons.org/licenses/by/4.0/). 